
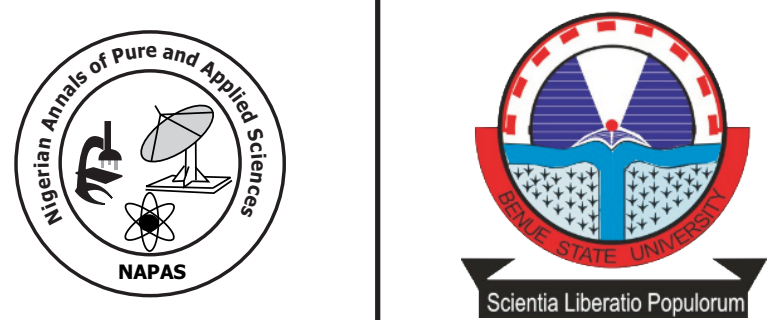

\title{
Assessment Of 2,2-Diclorovinyl Dimethyl Phosphate Content in Selected Phaseolus Vulgaris Samples Sold in Benue State Nigeria
}

\author{
Adoga, S.0 ${ }^{* 1}$, Ikese, O.C $^{1}$, Otache, M.A ${ }^{2}$, Igbum, $0 . G^{1}$, Otikwu, E. and Ukah, B. ${ }^{3}$ \\ ${ }^{1}$ Department of Chemistry, Benue State University, Makurdi, Nigeria \\ ${ }^{2}$ Department of Chemistry, Michael and Cecilia Ibru University, Delta State, Nigeria \\ ${ }^{3}$ Center for Food Technology and Research, Benue State University, Makurdi, Nigeria \\ *Corresponding author:adogasundayo@gmail.com or soadoga@bsum.edu.ng
}

\section{Abstract}

The presence of 2,2-Dichlorovinyl dimethyl phosphate (DDVP), popularly called, dichlorvos, in selected dry bean (Phaseolus vulgaris) samples was investigated in order to ascertain the levels of the contaminant in dry beans sold locally in Benue State, Nigeria. The samples were analyzed using gas chromatographymass spectrometry after the preparation of internal standard containing a mixture of acetone and diethyl pimelate, and 2,2-dichlorovinyl dimethyl phosphate standard. Dichlorvos was present in samples A, B, C and $D$ at levels $3.0 \times 10^{-5}, 2.7 \times 10^{-5}, 9.0 \times 10^{-6}$ and $1.6 \times 10^{-5} \mu \mathrm{g} / \mathrm{mL}$ respectively. However, these amounts fell within the safe limits for consumption $(0.01 \mathrm{mg} / \mathrm{kg}, 0.02-2 \mathrm{ppm})$, recommended by the European Food Safety Authority and United States Environmental Protection Agency. The contaminant was not found within the detectable limit of the instrument in samples $\mathrm{E}$ and $\mathrm{F}$ that were washed before cooking. Although, the contaminant was found below the recommended safe limit, its presence in the studied samples nevertheless, constitute health risk for consumers.

Key words: 2,2-Dichlorovinyl dimethyl phosphate, Beans, GC-MS, Contaminant, Benue State 


\section{Introduction}

Dichlorvos (2,2-Dichlorovinyl dimethyl phosphate) is a synthetic organophosphate compound which is widely used as an insecticide and is effective against a spectrum of pests. It is used in some parts of the world especially in developing countries to protect stored produce from insects' attack (Alavanja et al, 2004). It is one of the most commonly used organophosphate pesticides in developing countries, and is classified by WHO as a class IB, 'highly hazardous chemicals' (Suchismita Das, 2013). In Nigeria, and particularly, in the northern parts it is used as insecticide against mosquitoes and as food preservative for over a decade (Foll et al, 1965). Dichlorvos analysis on grains in the Country became necessary particularly for local consumers' safety and as a result of the compound presence on dry beans and a ban placed on dry beans exportation from Nigeria by European Union (NAQS, Vanguard Newspaper, March, 21, 2016). Dichlorvos (2,2-Dichlorovinyl dimethyl phosphate) was found as the active ingredient in the locally formulated pesticide, called ota pia-pia by Nigerians to control mosquitoes (Musa et al, 2010). It is reported to be found on grains, when used as preservative for such grains, and it is poisonous with associated health problems like constant respiratory and stomach action, inhibition of cholinesterase enzyme, and further absorption to the nerves and muscular systems when swallowed, inhaled, or absorbed (Gillett et al, 1992, WHO, 1979, Schwet et al, 1979, Schmidt et al, 1979 and Reeves, 1982). There was a report of highlevels of pesticide residues due to improper application and regular sprays of sub lethal doses responsible for poisoning and deaths of people in rural and urban areas of Borno State and Nigeria in general. Concerted efforts by the National Agency for Food and Drug Administration and Control (NAFDAC) unravel this ugly development, and traced the source of the poison to offensive beans from Taraba State (Northeastern Nigeria). Also, in April 2008, the national dailies reported a case involving one hundred and twenty (120) students of Government Girls Secondary School, Doma in Gombe Metropolis that were rushed to Gombe Specialist Hospital after consuming a meal of beans suspected to have been preserved with poisonous chemicals. Thorough investigation and laboratory testing/analysis by officials of the NAFDAC, revealed that the samples of both the cooked and uncooked beans contained outrageously high levels of organochlorinated pesticide. How this deadly compound found its way into the food chain was a puzzle (Stephen et al, 2012)

Dichlorvos was synthesized in the late 1940 s, as impurity in the pesticide trichlorfon (Reeves, 1982). But its commercial production started in $1950 \mathrm{~s}$ and, it is produced by dehydrochlorination of trichlorfon in aqueous alkali at $40{ }^{\circ} \mathrm{C}$ and by reacting trimethyl phosphate with chlora (Reeves, 1982). It is commonly referred to as DDVP, an abbreviation for 2,2Dichlorovinyl dimethyl phosphate. This organophosphate compound is available in other formulations as aerosol and soluble concentrates (Hanna et al, 1994 and Bhat et al, 2012).

\section{Materials and methods}

Dry bean (Phaseolus vulgaris) samples were bought randomly, prepared and labelled A, $\mathrm{B}, \mathrm{C}, \mathrm{D}, \mathrm{E}$ and $\mathrm{F}$ from the sixteen major markets across the three geopolitical zones of Benue State. Stones and other extraneous materials were handpicked and the samples homogenized to particle size using mortar and pestle.

\section{Preparation of standard solutions}

A solution of acetone containing diethyl pimelate at a concentration of $4.0 \mu \mathrm{g} / \mathrm{mL}$ was prepared and used as the internal standard as reported by Provisional CIPAC method 1981-The Dichlorvos Panel of PAC-UK. This was made sufficient for all calibration and sample solutions.

Also, analytical grade, 2,2-Dichlorovinyl dimethyl phosphate, popularly called sniper marketed in Nigeria by Swiss-Nigerian Chemical Company was used to prepare the calibration standard. This was done by measuring 0.200 and $0.250 \mathrm{~mL}$ into two (2) $50 \mathrm{~mL}$ separate volumetric flasks. To each flask, $25 \mathrm{~mL}$ of the internal standard was added with the aid of a pipette, and the volume diluted to the mark with acetone, followed by thorough mixing.

A $0.220 \mathrm{~g}$ of each sample was weighed into two (2) separate $50 \mathrm{~mL}$ volumetric flasks using the same pipette to prepare the dichlorvos calibration solutions, and $25 \mathrm{~mL}$ of the internal standard solution was added to each flask. The volume was diluted with acetone and mixed thoroughly, then, $1 \mathrm{~mL}$ from each flask was used for GC-MS analyses, at Shimadzu Training Centre for Analytical Instruments (STC), Lagos, Nigeria.

\section{Results}


Table 1: Dichlorvos content of beans samples sold in Benue State of Nigeria

\begin{tabular}{lll}
\hline S/No & Sample & Conc. $(\mu \mathrm{g} / \mathrm{mg})$ \\
\hline 1 & A & $3.0 \times 10^{-5}$ \\
2 & B & $2.7 \times 10^{-5}$ \\
3 & C & $9.0 \times 10^{-6}$ \\
4 & D & $1.6 \times 10^{-5}$ \\
5 & E & ND \\
6 & F & ND \\
\hline
\end{tabular}

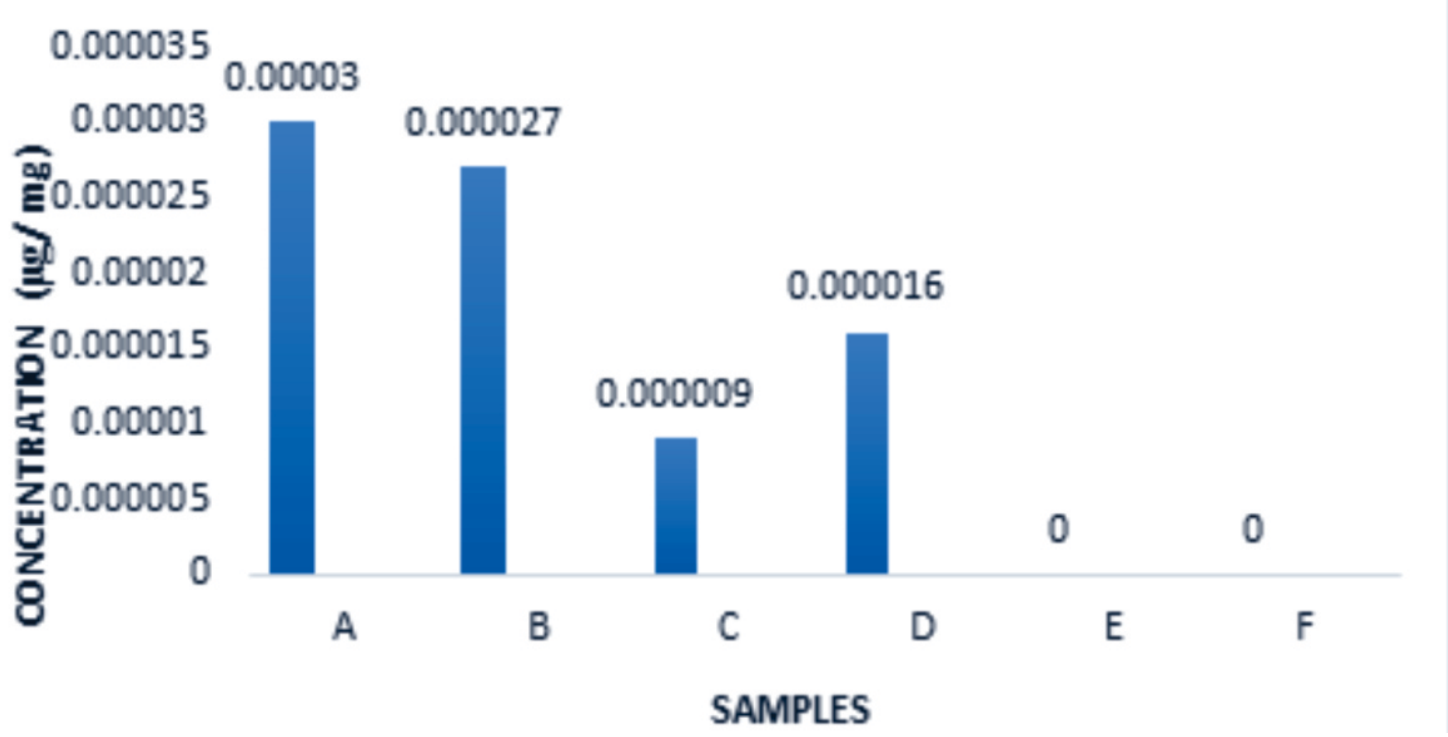

Figure 1: Samples dichlorvos concentration chart

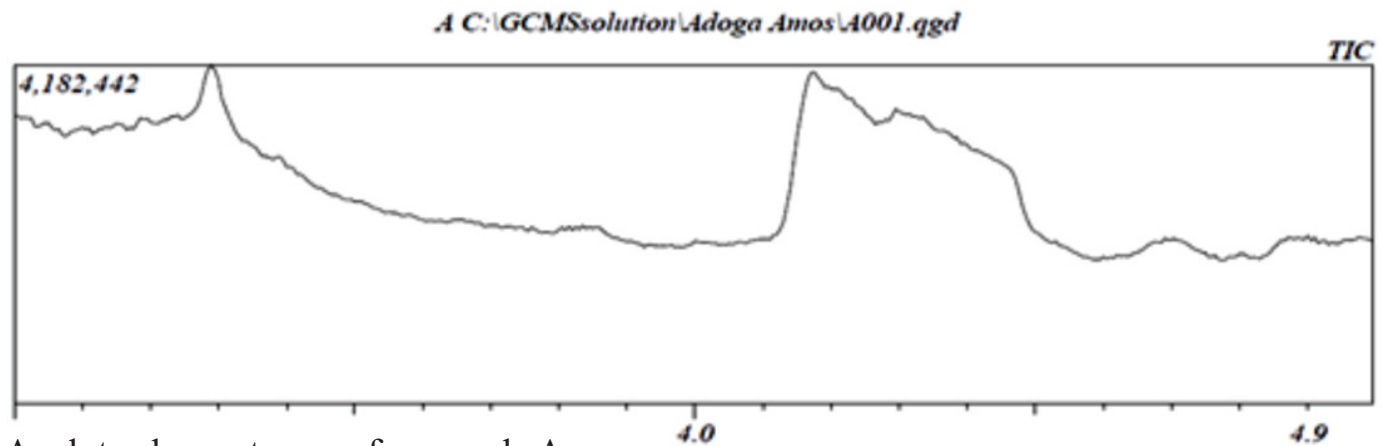

Figure 2. Analyte chromatogram for sample A TIC

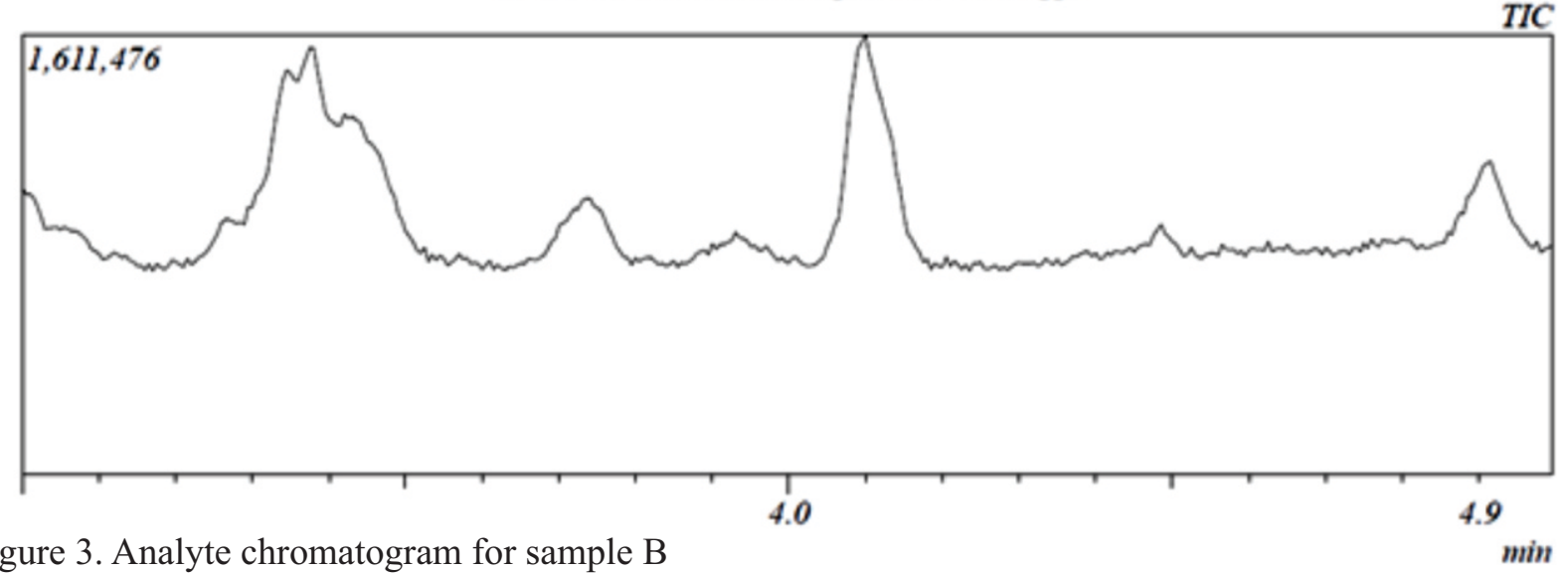

Figure 3. Analyte chromatogram for sample B 


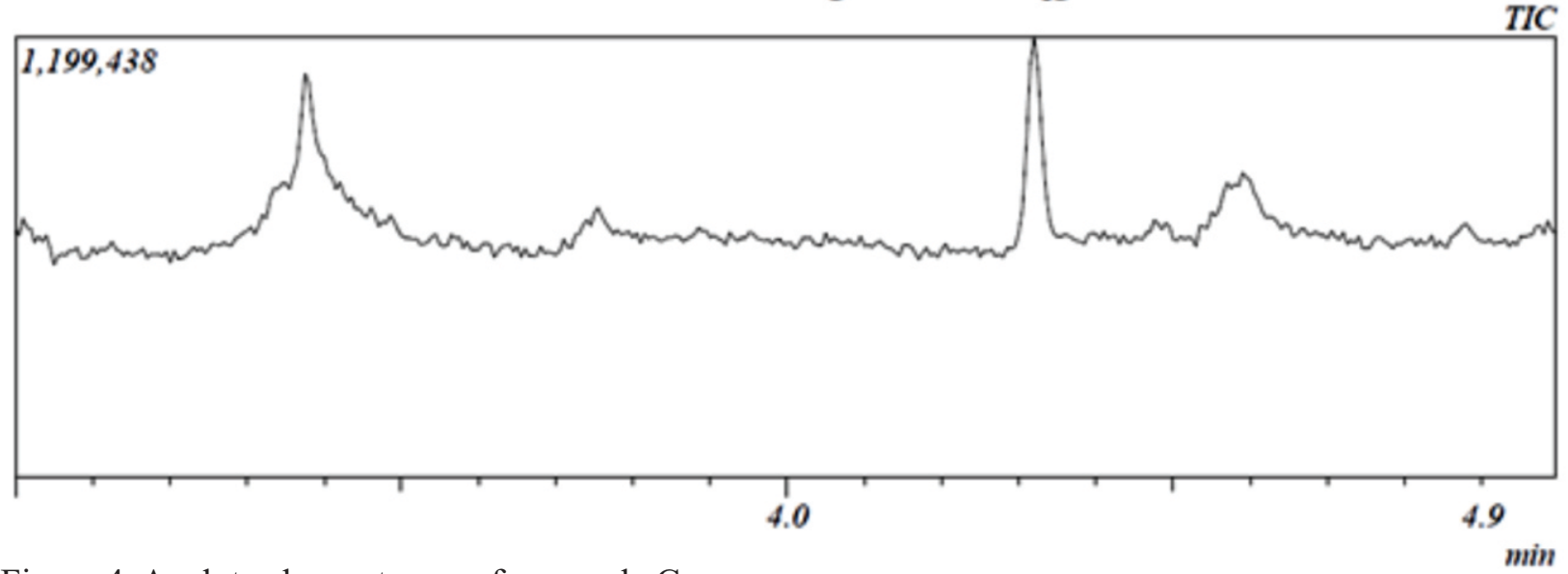

Figure 4. Analyte chromatogram for sample C

D C: IGCMSsolution LAdoga Amos D004.qgd

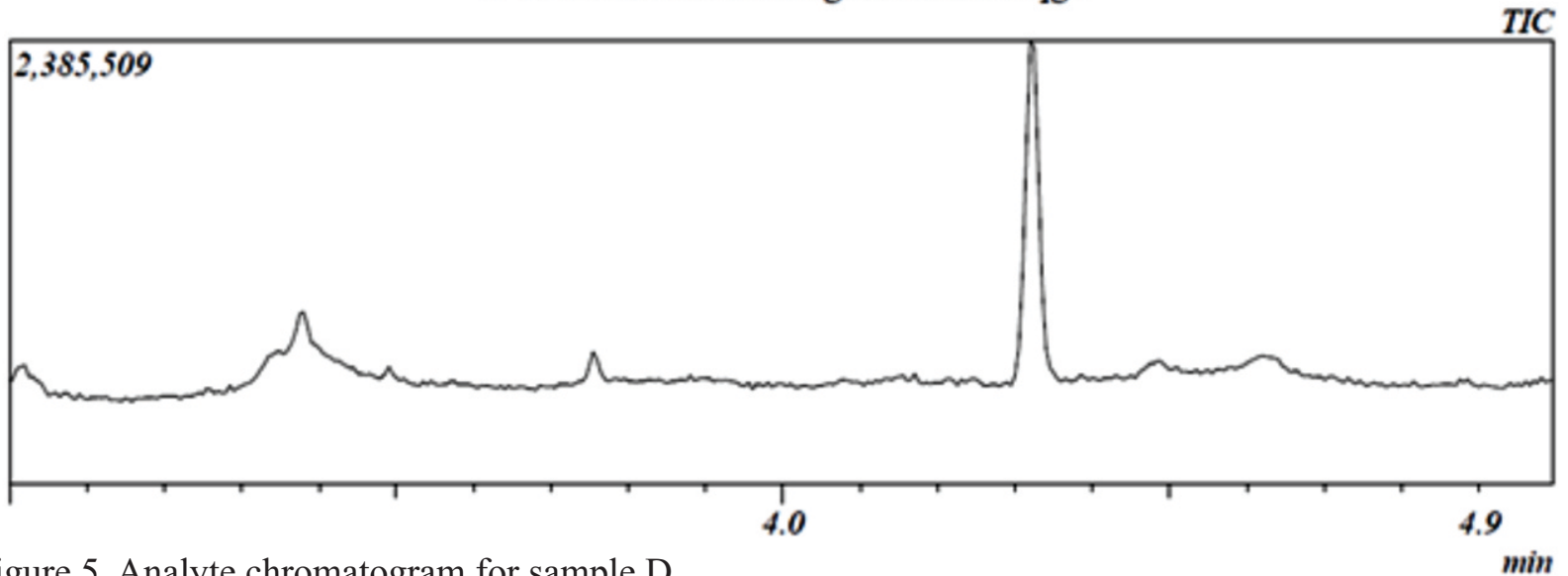

Figure 5. Analyte chromatogram for sample D

E C:IGCMSsolution LAdoga Amos $\mid$ sumday005.qgd

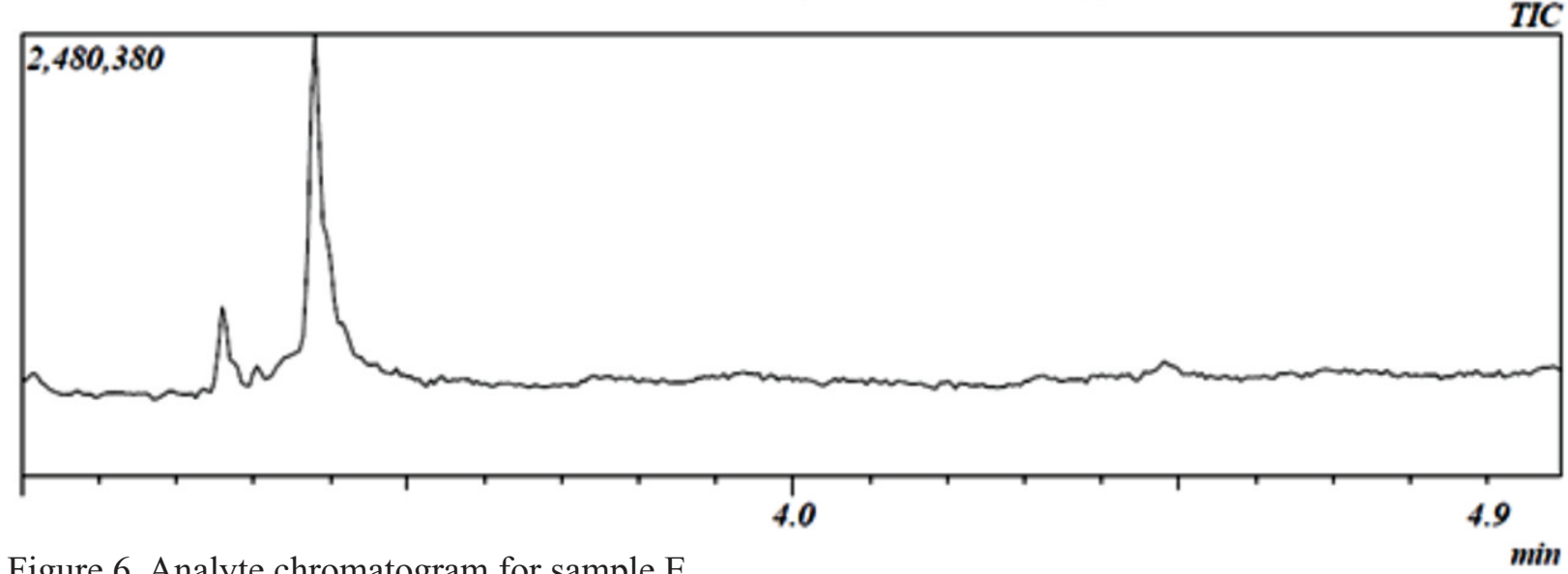

Figure 6. Analyte chromatogram for sample E

F C: IGCMSsolution LAdoga Amos Isunday006.ggd

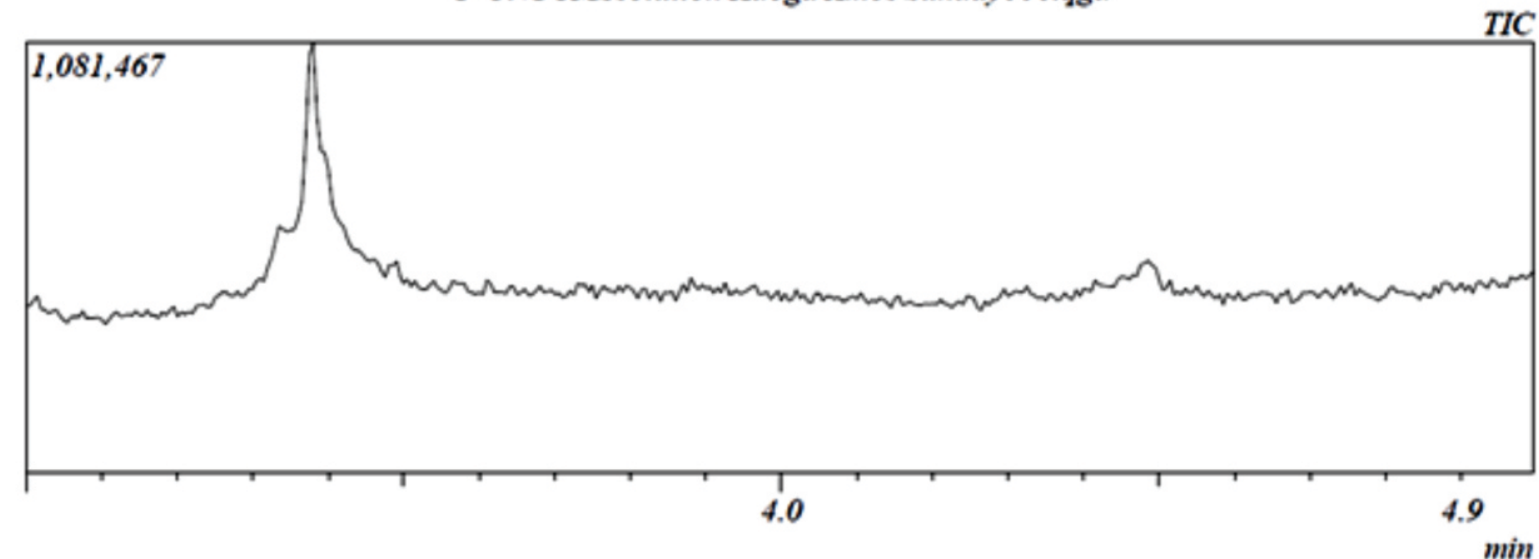

Figure 7. Analyte chromatogram for sample F 


\section{Discussion}

The peak area values detected are directly proportional to the concentration of the analyte in the samples. The peak areas were observed as seen in Table 1 and appendices II to IV, to be 92,55 and 30 for samples B, D and C respectively; sample B has the highest peak area and a corresponding concentration of $2.7 \times 10^{-5} \mu \mathrm{g} / \mathrm{mL}$, followed by sample $\mathrm{D}$, with a concentration of $1.6 \times 10^{-5}$ $\mu \mathrm{g} / \mathrm{mL}$, and sample $\mathrm{C}$ has the least analyte concentration, $9.0 \times 10^{-6} \mu \mathrm{g} / \mathrm{mL}$, (Table 1). Although, sample A, showed a broad peak (Figure 2 and appendix I) and no peak area value, it has the highest analyte concentration, $3.0 \times 10^{-4} \mu \mathrm{g} / \mathrm{mL}$ as observed in Table 1, when compared with samples B, C, D, E and F. Samples E and F showed zero (0) retention time, not detected analyte concentration, zero (0) peak and height areas, as seen in Table 1, Figures 6 and 7. Perhaps a negligible analyte quantity was detected in four (4) samples (A, B, C and $\mathrm{D})$, the concentration detected was within the safe limit of ' $0.01 \mathrm{mg} / \mathrm{kg}^{\prime}$ concentration recommended by European Food Safety Authority (EFSA). Samples E and F showed "not detected" (ND) concentration; this implies that, the analyte concentration in the samples was below the detectable limit of the instrument, and therefore, no peak was observed, as seen in the Table. This is an indication that washing as a pre-cooking procedure could possibly be effective in eliminating the presence of the contaminant in the Phaseolus vulgaris samples studied.

Dichlorvos values in this study were however, far less than values reported for related studies on vegetables (lettuce and cabbage) sold in Lusaka, Zambia, in which the dichlorvos residue levels were above the safe limit (Davies, 2016). The mean dichlorvos residue levels in the study for lettuce and cabbage were 5.23 and $6.35 \mathrm{mg} / \mathrm{kg}$ respectively, and were significantly higher than the maximum residue limit $(\mathrm{p}<0.05)$. Also, in another study on the use of acetyl cholinesterase inhibition assay for the detection of dichlorvos in durum wheat samples by a simplified extraction procedure, the detection of dichlorvos in the contaminated samples was at the maximum residue limit of $2 \mathrm{mg} / \mathrm{kg}$ and other well below (Del Carlo et al, 2006). One other related study on dichlorvos analysis by electrochemical biosensor and gas chromatography, dichlorvos extracted from milled wheat with hexane was filtered and the filtered extract was directly analyzed by gas chromatography using nitrogen-phosphorus flame detection; in the study, the recoveries of dichlorvos from milled wheat spiked at $0.25-1.5$ microgram/g ranged from 96.5 to $100.9 \%$, and the limit of detection was $0.02 \mathrm{microgram} / \mathrm{g}$
(Longobardi et al, 2005). In the study for dichlorvos analysis by gas liquid chromatography and flame photometric detection method, in food arising from the domestic use of dichlorvos PVC strips under practical conditions in UK and France, the residue concentration of less than 0.1 ppm was shown. In the UK trial, the mean dichlorvos levels in samples taken 7, 42, and 70 days after the strips were hung were $0.03,0.03$ and $0.02 \mathrm{ppm}$ respectively. In the French trial, the mean concentrations were a little lower, being $0.02,0.02$ and less than $0.01 \mathrm{ppm}$ at the same time (Elglar et al, 1972). In the study, the residue concentration in a sample did not appear to be correlated with the food items or with the manner of processing, and the study was a trial under practical conditions to determine the residues of dichlorvos that occur in food prepared from kitchens in which strips were placed (Elglar et al, 1972). Although, dichlorvos concentrations were less in this current study when compared with similar works done elsewhere and were observed to fall below the safe limit concentration, the detection of dichlorvos in the studied samples is of great health concern; partly, due to possible accumulation from regular consumption of the food item, different body biochemical composition and chemistry. Again, the items of food, the method of analysis, the detection limit of the instrument, the nature of the compound analyzed (dichlorvos and dichlorvos residue) and the way in which they were processed varied widely from sample to sample, place to place and from method to method. Therefore, they should be concerted effort from the government, through the regulatory agencies and the farmers to eliminate the contaminant entirely from the food chain.

\section{Conclusion}

The analysis of Phaseolus vulgaris samples sold in Makurdi metropolis of Benue State, Nigeria showed the presence of 2, 2-dichloro vinyl dimethyl phosphate (DDVP) contaminant. Although, the contaminant is present below the recommended safe limit, its presence nevertheless, constitute health risk for consumers due to possible accumulation of the contaminant from regular intake. Also, the use of the compound as preservative should be proscribed in Nigeria and regulatory agencies ensured compliance by farmers.

\section{Acknowledgement}

I wish to acknowledge the efforts and the contribution of the technologists in the Department of Chemistry, Benue State University, Makurdi, Nigeria, the analyst, Mr. Benedith 
Odjobor, of the Shimadzu Training Centre for Analytical Instruments (STC), Lagos, Nigeria, the Head of Chemistry Department, Benue State University, Makurdi and Miss Ukah Blessing.

\section{References}

Alavanja M.C., Hoppin J.A, Kamel F. (2004). Health effects of chronic pesticide exposure: Cancer and neurotoxicity. Annual review on Public Health, 25:155-197.

Suchismita Das (2013). A Review of Dichlorvos Toxicity in Fish. Current World Environment 8(1), 143-149

Foll C.V., Pant C.P, Lietaert P.E. (1965). A large scale field trial with dichlorvos as a residual fumigant insecticide in Northern Nigeria. Bull WHO, 32(4):531-550.

Nigeria Agricultural Quarantine Service report, (2016). Vanguard Newspaper, March, 21, 2016.

Umar Farouk, Stephen S. Hati, Abdullahi Mustapha, Garba Magaji (2010). Dichlorvos concentrations in locally formulated pesticide (Ota-piapia) utilized in northeastern Nigeria. Scientific Research and Essay Vol. 5(1), pp. 049-054

W. Gillett, James; R. Harr, James,T. Lindstrom, Frederick; A. Mount, Darl; D. St Clair, Akos; J. Weber, Lavern (1992). "Evaluation of Human Health Hazards on the Use of 2, 2 dichlorovinyl dimethyl phosphate (DDVP), Especially in Resin Strips". Residue Review 44:115-159

WHO. International programme on chemical safety, WHO Recommended classification of hazard and Guidelines to classification 1994-1995, UNEP/ILO/WHO(1992).

Schwet B.A., H.D. loset B.K.J. leong and R.E stapble (1979).Teratogenic potential of dichlorous given inhalation and gauge to mice and rabbit.Teratology.2038 3-385
Schmidt G.M.Schmidt.M.Nenner and F.vetterlein, 1979. Effect of dichlorvos (DDVP) inhalation on the activity of acetylcholinesterase in the bronchial tissues of rats. Arch, Toxicol.42 (3): 191-198

Reeves, (1982). House hold insecticides associated blood dyscariasis in children. American journal of pediatric hematology, 4(4):438-439.

Obida M. Gwary, Stephen S. Hati, Goni A. Dimari and Victor O. Ogugbuaja (2012). Pesticide Residues in Bean Samples from Northeastern Nigeria. ARPN Journal of Science and Technology. 2: (2):79-84

Bhat BA, Verma A, Saxena G. A. (2012). Comparative study on the toxicicity of a synthetic pesticide, dichlorvos and a neem based pesticide, neemon to labeorohita (Hamilton).curr world environment 2012 ;) 1):157-161

Provisional CIPAC method 1981-Prepared by the Dichlorvos Panel of PAC-UK

Davies Mwazi Sinyangwe, Boniface Mbewe, and Gibson Sijumbila (2016). Determination of dichlorvos residues in vegetables sold in Lusaka, Zambia. The Pan Afri Medical Journal. 2016; 23:113.

Del Carlo M, Pepe A, De Gregorio M, Maxini M, Marty JL, Fournier D, Visconti A, Compagnone D (2006). An electrochemical bioassay for dichlorvos analysis in durum wheat samples. J Food Prot. 2006; 69(6): 1406-11

Longobardi F, Solfrizzo M, Compagnone D, Del Carlo M, Visconti A, (2005). Use of electrochemical biosensor and $\mathrm{gc}$ for determination of dichlorvos in wheat. $J$ FoodProt.

K.E. Elglar, B. L. Mathews, P. Bosio (1972). Dichlorvos residues in food arising from the domestic use of PVC stips. Pest Management Science. Wiley Online Library 